\title{
Crick and Darwin's shared publication in Nature
}

A humble cockle and the family link between two minds that explored the origins of life.

Sir-Many of the published eulogies to the recently departed Francis Crick, mine included, have compared him to other scientific greats, such as Charles Darwin. I discovered only recently that Charles Darwin's last publication was, in effect, a joint publication with Francis Crick's grandfather.

On 18 February 1882, Walter Drawbridge Crick, an amateur malacologist and professional shoe manufacturer living in Northampton, wrote to Darwin to say that he had found a small freshwater cockle attached to the leg of a water beetle. Darwin was always interested in how freshwater animals, and molluscs in particular, dispersed by hitch-hiking on other animals.

The issue mattered because freshwater invertebrates vary surprisingly little from one region of the world to another. This could mean either that the diffusion of freshwater shells "took place before the present distribution of land and water", as suggested by John Gwyn Jeffreys in his British Conchology (van Voorst, London, 1862-1869) - or that there is frequent dispersal and population mixing, as argued by Darwin.

Crick's grandfather guessed rightly that Darwin would be interested in the water beetle's passenger. Darwin replied with a barrage of questions. Crick sent him the beetle and the shell, both of which survived the journey. Darwin sent the shell to Gwyn Jeffreys for identification, but Gwyn Jeffreys was away from home and the shell was returned by a servant, broken. Crick, who knew his molluscs, had already identified it as Sphaerium corneum, which
Darwin knew by its synonym of Cyclas cornea. Crick, meanwhile, had returned to the pond where he caught the beetle and found a dead frog with a bivalve of the same species clamped to its foot.

On 6 April 1882, Darwin's note “on the dispersal of freshwater bivalves" appeared in Nature. As well as describing Crick's peripatetic cockles, Darwin recalled the extraordinary fact that he had caught a freshwater beetle (of a different genus) while on HMS Beagle, 45 miles from land.

Thirteen days later, Darwin died. Crick died in 1903 at the age of 46, fifty years before his grandson co-discovered a cosmopolitan, universal code shared by all living creatures. Matt Ridley

Blagdon, Seaton Burn,

Newcastle upon Tyne NE13 6DD, UK

\section{It's the science that's a disaster in the movies ...}

Sir - Your News Feature "Hollywood or bust" (Nature 430, 720-722; 2004) looks at the latest attempts to wed science and Hollywood. As a newspaper science writer, I would urge that any such marriage be quickly annulled.

In 1996 I wrote a non-fiction popular book on the science of tornado and severe storm research. Being a film buff, I was delighted when the book was acquired as the official tie-in book for the Warner Brothers film Twister.

Later, to my embarrassment, I saw the film and was horrified by its manglings of meteorological science and terminology. And yet these same film-makers had bragged about "consulting" respected meteorologists.

Even a scientist as influential as Carl Sagan struggled, not entirely successfully, to preserve verisimilitude in the film version of his novel Contact. The movie Contact omits the novel's most haunting premise, which concerns the value of $\pi$. Why? Because (as one of the film's top producers later assured me) $\pi$ - a concept taught in every American high school - is too difficult for audiences to grasp. What remark better expresses Hollywood's contempt for its audience?

And it's only getting worse. As film budgets soar, a studio's future might depend on the success of a single blockbuster. Thus scriptwriters are increasingly pressured to erase any dialogue that might bore or confuse lowbrow viewers. In a business as cruelly capitalistic as filmmaking, what alternative do they have?

As the late John Gregory Dunne observed, on the basis of his many Hollywood experiences, no aesthetic or intellectual argument can withstand the movie mogul's favourite counterblast: "It's our money."

If Hollywood calls your laboratory, hang up.

Keay Davidson

San Francisco Chronicle, 901 Mission Street,

San Francisco, California 94103, USA

\section{... yet even flawed films raise interest in research}

Sir - We read with great interest your News Feature "Hollywood or bust" (Nature 430, 720-722; 2004) on scientists attending a screenwriting class. We use movies to teach non-science students some basic science in a course called Science and Cinema.

Movies are a wonderful medium for sparking the interest of students. We use films such as Outbreak to teach students about viruses, Jurassic Park to discuss cloning, Gattaca for genetic screening and next year The Day After Tomorrow will be used to introduce the science of climate change. Those familiar with these films will agree that the cinematic quality is variable and the representation of the science sometimes flawed - but all the films build an exciting story around a scientific centrepiece, and hence are an excellent teaching tool.
As scientists, we understand the concern that movies may misinform the public and that the profession is not accurately represented on the screen. We need to keep these things in perspective, however. Movies usually tell larger-thanlife stories and exaggerate characters. Is the work of a lawyer more accurately portrayed in films than that of a scientist? Scientists must join a long list of professions stereotyped by the movie industry.

Furthermore, to assume that most viewers don't understand that movies distort science in the same way that they distort historical events is somewhat patronizing.

In Cinema and Science, the students are taught some basic principles of a discipline; spotting the flaws in the movie is for many participants the most rewarding bit. We find it is often the flaws that inspire non-science students to want to know more about the current scientific research, the future possibilities and the responsibilities that come with them.

Let's use the excitement of movies to increase the understanding of science in the general public, rather than focus on the inevitable errors.

J. Justin Gooding, Katharina Gaus School of Chemistry and Centre for Vascular Research, The University of New South Wales, Sydney, New South Wales 2052, Australia

\section{correspondence}

Contributions to Correspondence may be submitted to corres@nature.com. They should be no longer than 500 words, and ideally shorter. Published contributions are edited. 